\title{
Thyroid Disorders and Development of Cognitive Impairment: A Review Study
}

\author{
Hossein Khaleghzadeh-Ahangar ${ }^{a, b} \quad$ Anis Talebic ${ }^{c}$ Parvaneh Mohseni-Moghaddam $^{d}$ \\ aDepartment of Physiology, School of Medicine, Babol University of Medical Sciences, Babol, Iran; bImmunoregulation

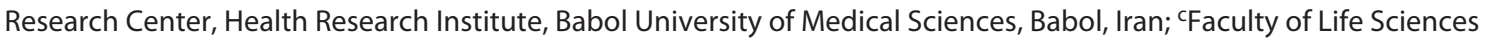 \\ and Biotechnology, Shahid Beheshti University, Tehran, Iran; ${ }^{\mathrm{d} D e p a r t m e n t}$ of Physiology, Faculty of Medicine, Tehran \\ Medical Sciences, Islamic Azad University, Tehran, Iran
}

\section{Keywords}

Dementia · Cognitive impairments · Thyroid disorders .

Hypothyroidism $\cdot$ Hyperthyroidism

\begin{abstract}
Dementia is a neurological disorder that is spreading with increasing human lifespan. In this neurological disorder, memory and cognition are declined and eventually impaired. Various factors can be considered as the background of this disorder, one of which is endocrine disorders. Thyroid hormones are involved in various physiological processes in the body; one of the most important of them is neuromodulation. Thyroid disorders, including hyperthyroidism or hypothyroidism, can affect the nervous system and play a role in the development of dementia. Despite decades of investigation, the nature of the association between thyroid disorders and cognition remains a mystery. Given the enhancing global burden of dementia, the principal purpose of this study was to elucidate the association between thyroid disturbances as a potentially modifiable risk factor of cognitive dysfunction. In this review study, we have tried to collect almost all of the reported mechanisms demonstrating the role of hypothyroidism and hyperthyroidism in the pathogenesis of dementia.

(c) 2021 S. Karger AG, Basel
\end{abstract}

\section{Introduction}

\section{Background}

Cognitive impairment is defined as low performance in one or more cognitive behavior that may not disrupt one's daily tasks completely; if it develops, in its more advanced state can be called dementia which includes severe or more severe forms of cognitive impairment/decline [1]. Dementia is a condition in which gradually amnesia and cognitive impairment occur. It also affects individuals, their families, and the economy, with global costs [2]. Worldwide, almost 50 million individuals suffer from dementia, and annual new cases are about 10 million people [2]. The prevalence of dementia in populations is expected to increase with increasing life expectancy [3]. On the basis of the WHO report, the onset of dementia symptoms in up to $9 \%$ of the cases is before the age of 65 years [4]. Dementia and cognitive decline prognosis include frontotemporal lobe dementia, neurodegenerative processes such as Alzheimer's disease (AD), and Lewy body dementia [5].

Patients with endocrine disorders may experience neurologic diseases [6]. Among endocrine disorders, thyroid disorders have been known as risk factors for progressive cognitive impairment development, either in the form of hyperthyroidism or hypothyroidism [7]. The present article tries to review the relationship between thyroid disorders with dementia and cognitive impairments.

Correspondence to

Parvaneh Mohseni-Moghaddam,p.mohseni@iautmu.ac.ir 
Thyroid Hormones and Their Receptors

Hormones secreted by the thyroid gland, which include thyroxine (T4) and tri-iodothyronine (T3), are essential for various body activities, from prenatal development such as growth and differentiation of the nervous system to adulthood functions such as metabolic rate maintenance, feeding, thermogenesis, memory and concentration, reactive oxygen species balance, and cardiovascular function as well [8]. T4, T3, and a very limited amount of reverse T3 are separated from the thyroglobulin molecule by lysosomal proteases and then released into the bloodstream [9]. The main form of the thyroid hormones in the circulation is T4, characterized by a longer half-life than T3 [10]. T4 is chiefly bound to proteins in the bloodstream and is carried to the target tissues; the amount of free $\mathrm{T} 4$ in the circulatory system is about $0.03 \%$ of total T4 [11]. The metabolically active thyroid hormone is T3, and like T4, most of the T3 in the circulation is attached to the proteins [12]. T4 and T3 are formed in the thyroid gland as a result of coupling reaction: monoiodotyrosine and di-iodotyrosine (DIT) join to form T3, and two DIT molecules form T4 [13]. While a small amount of T4 is converted to T3 in the thyroid gland, the conversion of T4 to its biologically active form occurs predominantly in extrathyroidal tissues, including the liver, kidney, central nervous system (CNS), pituitary gland, and skeletal muscles [14]. The physiological functions of thyroid hormones are mostly conducted via T3 interaction with nuclear receptors of thyroid hormones, which are present in four isoforms, including $\alpha 1, \beta 1, \beta 2$, and $\beta 3$. The mentioned receptors are characterized by transcription factor activity, in which their activity is modulated by the presence of ligand T3 [8].

There are various target genes for thyroid hormones; many are essential in brain functions, and more than 1,100 are important in brain development [15]. Among genes that are regulated by thyroid hormones, several genes possessing remarkable functions in the nervous system can be mentioned; for instance, RELN by producing Reelin, an extracellular matrix protein, is implicated in neuronal migration in the brain [16]; the next one is a protein kinase $\mathrm{C}$ substrate, NRGN (RC3/neurogranin) [17], which is involved in the neuronal plasticity processes such as longterm potentiation (LTP) in the hippocampus [18]. The amyloid precursor protein (APP) gene, which produces the precursor of $\beta$-amyloid (A $\beta)$, is downregulated by T3 [19]. Laminin expression, the extracellular matrix protein binding to astrocytes surface, is regulated by thyroid hormones [20]. Brain-derived neurotrophic factor (BDNF) is a pivotal factor in the differentiation of several types of interneurons and synaptic plasticity, and its expression is regulated by thyroid hormones as well [21]. Neuroserpin, which inhibits tissue plasminogen activator (tPA), is upregulated by thyroid hormone [22]. Thyroid hormones also adjust neuromodulin/GAP-43 expression regulating synaptic plasticity and memory processes [23]. Thyroid hormones have nongenomic mechanisms of effects as well, such as activating $\mathrm{Ca}^{2+}$-ATPase, $\mathrm{Na}, \mathrm{K}^{+}$-ATPase, mitogenactivated protein kinases, integrin $\alpha v \beta 3$, and $G_{q}$ signaling, maintenance of actin cytoskeleton, human bone cell proliferation, airways smooth muscle cell proliferation, separation of cellular respiration, and metabolism [24].

\section{Thyroid Disorders}

Thyroid disorders have been determined to be among the most common diseases worldwide [25]. The incidence of thyroid disorders is approximately $0.2-8 \%$ in adults; with age, this rises and in women is higher than in men [25]. Most people with thyroid disturbances, ranging from hypothyroidism to hyperthyroidism, have autoimmune disease in iodine-rich areas [25]. Chronic autoimmune thyroiditis (Hashimoto's disease) is the most significant cause of hypothyroidism in iodine-sufficient regions [26]. Iodine deficiency is the most prevalent cause of goiter as thyroid dysfunctions, which leads to hypothyroidism in low-iodine areas [27]. Hypothyroidism and hyperthyroidism are usually triggered by pathological changes in the thyroid gland (the primary thyroid disorder) [28]. However, in rare cases, they can be caused by hypothalamus or pituitary gland disorders (secondary or central thyroid disorders) or by ectopic thyroid hormone secretion [29]. Based on the thyroid-stimulating hormone (TSH) and free T4 levels in the bloodstream, thyroid disorders are also categorized, which are mentioned in the following. Subclinical hypothyroidism is characterized when serum levels of TSH are higher than the normal range, but still, free T4 concentration is within the normal range of the population. Overt hypothyroidism is characterized somehow that serum concentration of TSH is higher than the normal range, and free T4 levels are lower than the normal range [30]. Similarly, the reverse hormone pattern is used to define overt hyperthyroidism (low serum TSH levels and high free T4 and T3 levels) and subclinical hyperthyroidism (low serum TSH level and normal free T4 and T3 levels) [31]. Subclinical thyroid diseases are more common than overt types; they are often asymptomatic and, hence, go undiagnosed and untreated, leading to significant adverse effects [32].

\section{Thyroid Disorders and Cognitive Impairments}

Psychological and cognitive changes have been documented for many years in adults with altered thyroid func- 
tion. In the late nineteenth century, the association of hypothyroidism and thyrotoxic diseases with mental disorders was reported for the first time [33, 34]. Although some studies have ruled out a correlation between thyroid hormones and cognition, it is confirmed that cognition is influenced by thyroid impairment [35]. Animal studies have demonstrated that adult hypothyroidism changes brain function and morphology in regions that affect cognitive functions [36]. In both hypothyroidism and hyperthyroidism, thyroid dysfunction plays a role in increasing the risk of AD development [37]. Other research studies showed that an increased risk of dementia was associated with both high and low TSH levels $[38,39]$. In a study performed on mild $\mathrm{AD}$ patients, thyroid hormones have moderately changed. The authors suggested that decreased peripheral conversion of T4 to T3 caused increased serum levels of free $\mathrm{T} 4$ with decreased $\mathrm{T} 3 / \mathrm{T} 4 \mathrm{ra}-$ tios. They also suggested that the serum level of T3 is related to brain structures involved in the development of $\mathrm{AD}$ [40]. It is also noteworthy that major cognitive and affective impairments, which affect various domains, are not characteristics of subclinical thyroid disorders. However, in subclinical thyroid disorder, subtle deficits in particular cognitive domains are likely to occur [41]. Cognitive and emotional indices can be significantly improved by using thyroid hormones in patients with thyroid disorders [42]. It was also reported that the T3 level is precisely regulated within a narrow range in the CNS [43]. It was suggested that slight deviations in normal brain T3 levels might lead to the cognitive deterioration [44]. Additionally, either reduced serum-free T3 or downregulating hippocampal thyroid hormone receptor signaling could develop cognitive and behavioral impairment in mice [45, 46]. Since the association between hyperthyroidism and/ or hypothyroidism with dementia has already been studied and is still being investigated, it is necessary to consider the underlying pathology and mechanisms of this association and thus modify the management of dementia. In the three following sections, hyperthyroidism and hypothyroidism and their relationship with cognitive problems and dementia, along with possible mechanisms, are discussed separately; first, because of the importance of thyroid hormone in brain development, the impact of hypothyroidism on brain development, especially at the regions related to cognition, is briefly reviewed.

\section{Hypothyroidism and Brain Development during the \\ Embryonic Period}

Throughout life, from fetus to senile, thyroid hormones have a multitude of effects on CNS development and mediate huge influences on the brain [47]. During pregnancy, before 12-14 weeks of gestation, the fetus is dependent on the mother's thyroid hormones $[48,49]$. It has been identified that $2.5 \%$ of women are affected by hypothyroidism during pregnancy, and the incidence of congenital hypothyroidism is approximately $1 / 3,500$ 4,000 births [25]. Experimentally induced thyroid hormone deficiency during sensitive stages of the fetus brain development decreases the number of neurons, dendritic arborization, and synaptogenesis and alters neuronal migration to the hippocampus and neocortex areas in rodents [50-53]. Thyroid hormone deficiency during early pregnancy by altering the neuronal migration leads to less well-defined cortical layering and also an alteration in the hippocampus and somatosensory cortex cytoarchitecture in rodents $[51,52]$. Diminished intelligence quotient scores, subtle deficits in cognitive function, and memory were observed in children born from women with hypothyroxinemia during pregnancy [54]. During pregnancy, induction of hypothyroidism in mice causes alterations in DNA hypermethylation of several essential brain genes, such as BDNF, which is crucial for various activities in the brain, including neuronal plasticity processes related to hippocampal-dependent learning and memory [55]. In humans, even a moderate subclinical maternal hypothyroxinemia, particularly in early pregnancy, causes permanent neural damage [54] in addition to delayed motor and mental development [56]. Thyroid hormone deficiency in late pregnancy has also demonstrated irreversible alterations in neuronal plasticity and transmission in the hippocampus of adult animals $[57,58]$.

\section{Postnatal Hypothyroidism and Brain Development}

The examination of the structural and growth properties of the hippocampus in the rats that were exposed to early postnatal thyroid hormone deficiency showed a substantial reduction in the surface of this area, and the regions of CA1 and CA4 were more vulnerable to the devastating effects of early thyroid deficiency [59]. Early postnatal development studies in rats have also shown that the granule cell number in the dentate gyrus of the hippocampus decreases in hypothyroid animals, and irreversible neuronal cell death occurs in the hippocampal CA1 area after postnatal hypothyroidism induction. Additionally, CA3 pyramidal cell layer volume was reduced, but cell number in this layer did not decrease $[60,61]$. The possible mechanisms involved in brain alterations due to developmental hypothyroidism are presented in Table 1. 
Table 1. Possible mechanisms through which hypothyroidism affects brain development
Decreasing the number of neurons, dendritic arborization, and synaptogenesis

Alteration in neuronal transmission

Alteration in neuronal migration to the hippocampus and neocortex

Alterations in DNA hypermethylation of several essential brain genes, such as BDNF

Irreversible alterations in neuronal plasticity

Reduction in the surface of the hippocampus, particularly in CA1 and CA4 regions

Neuronal cell death in the dentate gyrus and CA1

Reduction in the volume of CA3 pyramidal cell layer

\section{Search Strategy}

All 3 authors have used ScienceDirect, PubMed, Scopus, and Google Scholar search engines to obtain all published papers related to the subject. The search covered all articles (from past to present) that have been published online and are available through these websites. For all articles, we tried to access the full text and extract their methods and findings. Attempts were made to use all relevant articles that added new content. Keywords used were thyroid disorders, hypothyroidism, subclinical hypothyroidism, hyperthyroidism, subclinical hyperthyroidism, thyroxine, tri-iodothyronine, thyroid-stimulating hormone, thyroid autoimmunity, Hashimoto's disease, Hashimoto's thyroiditis, cognitive impairments, dementia, learning and memory impairments, brain development, Alzheimer's disease, $\beta$-amyloid, tau hyperphosphorylation, and related words and abbreviations. Furthermore, a combination of thyroid and cognitive-related words were used, such as thyroid disorders and cognitive impairment, hyper/hypothyroidism and cognitive impairment, and thyroid autoimmunity and cognitive impairment. Totally, 681 articles were found. Duplicated articles, articles with no concomitant relationships of dementia and thyroid hormones, articles with duplicated results, articles without available full text, and articles with newer versions were excluded. Ultimately, 83 articles were used. The authors tried to present and analyze the articles with no bias.

\section{Adult-Onset Hypothyroidism and Cognitive Impairments}

It has been shown that a variety of cognitive domains can be impaired by overt hypothyroidism. Several studies demonstrate reductions in attention/concentration, general intelligence, memory, language, perceptual function, executive function, and psychomotor activity. It is indicated that the most consistently influenced do- main is memory [62], with specific deficits in verbal memory $[63,64]$. According to studies, the prevalence of cognitive dysfunction is high among patients with hypothyroidism. Increased age, increased disease duration, and high levels of TSH are statistically related to cognitive deficits [65]. A previous study has shown various neuropathological signs of $\mathrm{AD}$ in adult rats with hypothyroidism, namely, hippocampal tau hyperphosphorylation and impaired signaling molecules expression related to synaptic plasticity and memory, as well as elevated levels of pro-inflammatory cytokines. Spatial memory is also impaired in hypothyroidism [66]. It has been documented that people with hypothyroidism have a 2-fold higher chance of $\mathrm{AD}$ [67]. Also, older individuals seem to be more susceptible to the cognitive consequences of subclinical hypothyroidism than the young population; treating hypothyroidism may protect the aging brain against cognitive dysfunctions. However, with L-thyroxine treatment, all the cognitive dysfunctions caused by thyroid disorder cannot be treated completely; it improves attention, memory, verbal fluency, reaction time, visual memory, and executive functions, but still, significant memory deficit can persist in middle-aged and older people [68]. It seems that the brain becomes more susceptible to thyroid disorders during aging; therefore, thyroxine treatment may not restore all aspects of cognitive dysfunctions [69]. Adultonset hypothyroidism in rats decreases hippocampal synaptic plasticity and diminishes learning as well [36]. Furthermore, in thyroidectomized adult rats, intense dysfunction in learning and both short-term and longterm memory was identified [70]. Thyroid hormone deficiency disrupts LTP in both early and late phases [71], so the memory encoding and consolidation may become disrupted. Belandia et al. [19] have reported that in a cell line of rat neuroblastoma, T3 negatively regulates APP gene expression. It seems that low levels of thyroid hormones in the CNS by elevating the expression of APP and, subsequently, A $\beta$ protein levels may predispose the patients to $\mathrm{AD}$ [72]. Additionally, an in- 
Table 2. Possible mechanisms through which hypothyroidism is involved in cognitive impairment

Hippocampal tau hyperphosphorylation

Impaired signaling molecules expression leading to reduced hippocampal synaptic plasticity and memory

Elevated levels of pro-inflammatory cytokines

Decreasing the numbers of dentate gyrus granule cells and CA1 pyramidal neurons in the hippocampus

Decrease in the apical dendritic spine density of pyramidal cell in the CA1 area

LTP disruption

Elevation in APP gene expression and, subsequently, $\beta$-amyloid

Decreasing the cerebral blood flow

Impairment in the hippocampal cholinergic neurons and also the synthesis of this neurotransmitter

Decrease in choline acetyltransferase activity

Alteration in the catecholamine, GABA, serotonin, tryptophan, neuromodulators, and growth factors in the hippocampus

Reduction in hippocampal $\mathrm{Na}^{+}, \mathrm{K}^{+}$-ATPase activity, and glutamate levels

Hippocampal tau protein hyperphosphorylation

Reduction in the expression of several genes such as laminin and BDNF

Glucose metabolism impairment

IL-1-dependent autophagy and apoptosis in hippocampal neurons

verse association between serum TSH levels, but not free $\mathrm{T} 3$ or T4, with blood flow in the inferior and middle areas of the right temporal lobe of patients with $\mathrm{AD}$ has been observed [73, 74]. Objective evidence provided by imaging studies shows that brain function and structure are altered in the hypothyroid state by reducing the volume of the hippocampus and cerebral blood flow, particularly in regions mediating visuospatial processing, attention, motor speed, and working memory [75-77]. Hypothyroidism may also impair the hippocampal cholinergic neurons, which are abundant in this area; additionally, choline acetyltransferase activity and the level of this enzyme involved in the synthesis of acetylcholine are reduced in hypothyroidism in rats [78]. By altering the expression of growth factors, neuromodulators, and neurotransmitters in the brains of the adult rats, thyroid dysfunction indirectly influences CNS activity, including regions implicated in cognitive and emotional functions [41, 79]. Decreased thyroid hormones, for instance, change the expression of enzymes in the hippocampus, which are involved in the regulation of catecholamine, GABA, and serotonin systems in rodents [79-81]. Hypothyroidism causes brain serotonin reduction and its precursor, tryptophan (5-HTP), as well [82]; since the brain serotonin system is a pivotal part of the memory improvement and cognitive behavior enhancer $[83,84]$, it can be a probable mechanism of hypothyroid-induced cognitive impairment. Hippocampal $\mathrm{Na}^{+}, \mathrm{K}^{+}$-ATPase activity, and glutamate levels are also reduced in hypothyroidism conditions which could be involved in memory deficit in mice [85]. Additionally, hippocampal-related memory deficits dis- played by hypothyroid rats were reduced by T3 supplementation, and key markers of thyroid function in the hippocampal tissue, including $A \beta$ production, neuroinflammation, and several signaling pathways identified to be implicated in memory function and neuronal plasticity, were normalized [86]. There is also evidence that thyroid hormones are implicated in the regulation of tau protein phosphorylation, another hallmark of $\mathrm{AD}$, and it was reported that hypothyroidism leads to hippocampal tau hyperphosphorylation $[66,86]$. Besides, there are various genes whose expression decreases with a decline in thyroid hormones, such as laminin, a guidance molecule implicated in the migration of neuronal cells [87], and BDNF, involved in the synaptic structural changes [21, 88, 89]; therefore, hypothyroidism may influence the cognition by altering neuronal migration and synaptic structure. In addition, hypothyroidism worsens cognition at any age by preventing energy (glucose)-consuming functions required for critical CNS activities, namely, neurotransmission, memory, and other higher brain function [68]. Hypothyroidisminduced disorders of glucose metabolism in several brain areas, including the hippocampus, may precede the clinical onset of dementia [90]. Furthermore, longterm developmental hypothyroidism from the embryonic period till adulthood triggers an interleukin1-dependent autophagy mechanism as an essential mediator which promotes apoptosis in hippocampal neurons and cognitive impairment in rats [91]. The possible mechanisms involved in cognitive impairments due to adultonset hypothyroidism are also presented in Table 2 . Treatment of overt hypothyroidism improves symp- 
toms of mood or cognitive deficits (although that may not be fully resolved); however, therapy for subclinical hypothyroidism is more challenging. In subclinical hypothyroidism, thyroid-related emotional or cognitive impairment is subtle (executive function and working memory); overt hypothyroidism, however, is related to a clinically considerable reduction in affective and cognitive function (particularly memory) [62].

\section{Thyroid Autoimmunity and Cognitive Impairment}

Thyroid autoimmunity is a multifactorial disease with genetic backgrounds and is influenced by several environmental factors; chronic lymphocytic thyroiditis, also called Hashimoto's thyroiditis (HT) or Hashimoto's disease, is the most common thyroid autoimmunity in humans in which most of them are euthyroid, and others show hypothyroidism [92]. HT occurs more frequently in adults and predominantly in women and girls. The HT is characterized by increased thyroid peroxidase antibody levels in the serum [93].

One of the HT consequences is encephalopathy [94]. In HT, mild cognitive impairment and subtle dementia may occur [93]. It influences visual attention, speech fluency, and conceptual tracking in humans [95]. During HT, cerebral metabolism changes, and thereupon, neural activity reduces [96]. It also can affect the human brain's bioelectrical activity [97, 98]; via altering neuronal activity, it can affect cognition. Furthermore, in compensated euthyroid HT patients also the cognitive dysfunction may occur [97].

\section{Adult-Onset Hyperthyroidism and Cognitive Impairments}

Some studies have reported that increased levels of free T4 or decreased levels of TSH are linked to cognitive dysfunction or dementia $[99,100]$. Kalmijn et al. [39] stated that subclinical hyperthyroidism raises AD and dementia risks among the elderly population. A 3 -fold increase in the risk of dementia of the Alzheimer type among all hyperthyroid participants was also presented [39]. Increased risk of dementia was found in hyperthyroid patients using large-scale registry-based data. Compared to people with a normal level of TSH, every 6 months of reduced TSH was associated with a $16 \%$ increased risk of dementia [101, 102]. Prolonged exposure to thyroid hormone can cause cardiovascular and cerebrovascular diseases such as systolic hypertension and fibrillation, associated with an increased risk of dementia [103, 104]. Imaging studies through magnetic resonance spectroscopy have demonstrated that Graves' patients have abnormal brain metabolism in the mid-frontal, mid-occipital, and parieto-occipital areas, which maps to the domains of working memory and executive function [105, 106]. Furthermore, Schreckenberger et al. [107], by using positive emission tomography scanning, reported an irregular glucose metabolism in the limbic system of the right hemisphere, a major site involved in long-term memory, in patients with Graves' disease. On the other hand, in a study performed by Zhu et al. [108], no difference was found in a specific and sensitive test of working memory or functional magnetic resonance imaging results in thyrotoxic patients compared with euthyroid controls. Other studies reported that higher levels of free T4 are associated with elevated rates of atrophy in the amygdala and hippocampus on MRI and increased neocortical neurofibrillary tangles and neuritic plaques at autopsy $[109,110]$. Additionally, hyperthyroidism by altering some genes' expression, such as neurogenesis ones, may cause dementia [104]. Another possible mechanism by which excess thyroid hormone may affect brain function is its effect on cholinergic neurons. Depleting acetylcholine and presynaptic cholinergic metabolites in the hippocampal tissue and cerebral cortex has been established in both hyperthyroid individuals with cognitive impairment and $\mathrm{AD}$ [110]. Arguing against these potential mechanisms, however, T4 administration in a mouse model of $\mathrm{AD}$ enhanced spatial learning and memory, antioxidant enzyme levels, cholinergic activity, ATP content, and survival of the neuronal cells [111]. It should be noted that in this study, the hormone was injected into mice for only 4 days, and the observed result could be related to the short-term effects of hyperthyroidism.

Increased neuronal death by thyroid hormone exposure and hyperthyroidism, resulting in reduced metabolites of antioxidants and induced oxidative stress, has also been indicated to cause cognitive impairment [35, 112,113 ]. Li et al. [114] demonstrated that participants with hyperthyroidism had remarkably higher circulating total tau protein levels than their euthyroid counterparts, which may be implicated in the pathogenesis of AD. Döbert et al. [115] reported an enhanced risk of dementia, particularly vascular dementia, in participants with reduced or borderline TSH levels. Neuroserpin, whose expression is enhanced by thyroid hor- 
Table 3. Possible mechanisms through which hyperthyroidism is involved in cognitive impairment

\author{
Cardiovascular and cerebrovascular diseases such as systolic hypertension and fibrillation \\ Abnormal brain metabolism \\ Atrophy in the amygdala and hippocampus \\ Increased neocortical neurofibrillary tangles and neuritic plaques \\ Alteration in gene expression \\ Depletion of acetylcholine and presynaptic cholinergic metabolites in the hippocampal \\ tissue and cerebral cortex \\ Increased neuronal death and reduction in antioxidant level \\ Higher levels of circulating total tau protein \\ Upregulation of neuroserpin
}

mones, has been indicated to be upregulated in $\mathrm{AD}$ [22]. This protein, by inhibition of tPA activity, results in decreased brain plasmin levels, one of the essential enzymes involved in the breakdown and clearance of $\mathrm{A} \beta$ and its plaques from the brain [22]. The possible mechanisms involved in cognitive impairments due to adult-onset hyperthyroidism are also presented in Table 3 .

Fukui et al. [116] reported that in a patient with overt hyperthyroid dementia, specific abnormalities related to AD were steadily normalized after correcting the hyperthyroid state. Also, it was strongly advised to assess thyroid function in patients with radiologically and clinically recognized $\mathrm{AD}$ because treatable and manageable hyperthyroid dementia might be overlooked [116]. In the two previously published studies, the authors claim that cognitive dysfunction has only been observed in subclinical hyperthyroidism and not in overtly hyperthyroid patients, which seems somewhat illogical. The authors believe that this disparity could be attributable to the fact that overt hyperthyroidism is almost always detected and handled immediately, whereas subclinical hyperthyroidism may not be treated for an extended period; as a result, the patient is exposed to an abnormal hormonal environment, albeit less deranged, for a more extended period $[117,118]$. Additionally, some studies connected dementia to a specific type of hyperthyroidism [101, 104], some studies connected subclinical hyperthyroidism to dementia $[39,118,119]$, and other ones indicate that overt hyperthyroidism with elevated free $\mathrm{T} 4$ is associated with dementia $[109,120,121]$. Some believe that hyperthyroidism dementia is because of TSH decline [101, 118], whereas another study does not confirm the association of thyroid disorders nor TSH with cognitive function [122]. Medication can readily treat subclinical hyperthyroidism despite diverse known risk factors that promote cognitive impairment [123]. Therefore, assessing thyroid function is an essential need, especially in the elderly population.

Thyroid Disorders and Cognitive Impairment

\section{Conclusion}

It should be fully emphasized that despite decades of widespread investigations, the elucidation of the relationship between thyroid function and cognition is not entirely conclusive. Many studies have shown that thyroid disorders cause cognitive impairment. Various mechanisms have also been suggested to show this association, including tau hyperphosphorylation, decreased neuron's number, alteration in DNA hypermethylation, shrinking different parts of the hippocampus, hippocampal neuron's death, LTP disruption, altered brain bioelectrical activity, decrease in Na, K-ATPase activity, abnormal brain metabolism and glucose consumption, upregulation of neuroserpin, altered neural activity, increased $A \beta$ levels, inflammation, oxidative stress, cell death, altered gene expression, changes in synaptic plasticity, decreased cerebral blood flow, cardiovascular and cerebrovascular diseases, abnormal brain metabolism, and changes in different neurotransmitters' levels. It seems that the brains of older people are more susceptible to thyroid alteration, and compensated euthyroid state may not restore all aspects of cognitive impairment caused by thyroid dysfunction. Therefore, assessing thyroid function is an essential need to avoid cognitive consequences. However, some other studies have denied this association, and some investigations have demonstrated that an increased risk of dementia is only associated with specific kinds of thyroid dysfunction such as subclinical hyperthyroidism and not all types of thyroid disorders. Therefore, further studies are needed to reveal the correct associations and identify the mechanism that causes this relationship.

\section{Conflict of Interest Statement}

There are no conflicts of interest. 


\section{Funding Sources}

This study did not receive any financial support.

\section{Author Contributions}

Hossein Khaleghzadeh-Ahangar has written the search strategy, thyroid hormones and their receptors, thyroid disorders, thyroid disorders and cognitive impairments, and conclusion sections and edited all of the manuscript. Anis Talebi has written the abstract and a part of the introduction section. Parvaneh MohseniMoghaddam has prepared the tables. She has also written the following sections including the other part of the introduction, hypothyroidism and brain development during embryonic period, postnatal hypothyroidism and brain development, adult-onset hypothyroidism and cognitive impairments, thyroid autoimmunity and cognitive impairment, and adult-onset hyperthyroidism and cognitive impairment. The original idea of the review was also designed by Parvaneh Mohseni-Moghaddam.

\section{References}

1 Knopman DS, Petersen RC. Mild cognitive impairment and mild dementia: a clinical perspective. Mayo Clin Proc. 2014;89(10): 1452-9.

2 Livingston G, Huntley J, Sommerlad A, Ames D, Ballard C, Banerjee S, et al. Dementia prevention, intervention, and care: 2020 report of the Lancet Commission. Lancet. 2020; 396(10248):413-46.

3 Radue R, Walaszek A, Asthana S. Neuropsychiatric symptoms in dementia. Handbook of clinical neurology. Elsevier; 2019. p. 437-54.

4 World Health Organization. Risk reduction of cognitive decline and dementia: WHO guidelines. 2019.

5 Molano JR, Kelley BJ. Dementia and systemic disorders. In: Lewis SL, editor. Neurological disorders due to systemic disease. WileyBlackwell; 2013. p. 51-76.

$6 \mathrm{Yu} \mathrm{J}$. Endocrine disorders and the neurologic manifestations. Ann Pediatr Endocrinol Metab. 2014;19(4):184

7 Eslami-Amirabadi M, Sajjadi SA. The relation between thyroid dysregulation and impaired cognition/behaviour: an integrative review. J Neuroendocrinol. 2021;33(3):e12948.

8 Cheng SY, Leonard JL, Davis PJ. Molecular aspects of thyroid hormone actions. Endocr Rev. 2010;31(2):139-70.

9 Dunn JT, Dunn AD. Update on intrathyroidal iodine metabolism. Thyroid. 2001;11(5): 407-14.

10 Irizarry L. Thyroid hormone toxicity. Endocrinology. 2014;2. Medscape WedMD LLC Retrieved.

11 Köhrle J. Local activation and inactivation of thyroid hormones: the deiodinase family. Mol Cell Endocrinol. 1999;151(1-2):103-19.

12 Robbins J. Factors altering thyroid hormone metabolism. Environ Health Perspect. 1981; 38:65-70.

13 Salamonczyk GM, Oza VB, Sih CJ. A concise synthesis of thyroxine (T4) and 3,5,3'-Triiodo-l-thyronine (T3). Tetrahedron Lett. 1997; 38(40):6965-8

14 Germain DLS, Galton VA. The deiodinase family of selenoproteins. Thyroid. 1997;7(4): 655-68.

15 Bernal J. Thyroid hormone regulated genes in cerebral cortex development. J Endocrinol. 2017;232(2):R83-97.
16 Alvarez-Dolado M, Ruiz M, Del Río JA, Alcántara S, Burgaya F, Sheldon M, et al. Thyroid hormone regulates reelin and dab1 expression during brain development. J Neurosci. 1999 Aug 15;19(16):6979-93.

17 Iniguez M, Rodriguez-Pena A, Ibarrola N, De Escobar GM, Bernal J. Adult rat brain is sensitive to thyroid hormone. Regulation of RC3/ neurogranin mRNA. J Clin Invest. 1992; 90(2):554-8.

18 Kaleka KS, Gerges NZ. Neurogranin restores amyloid $\beta$-mediated synaptic transmission and long-term potentiation deficits. Exp Neurol. 2016 Mar;277:115-23.

19 Belandia B, Latasa MJ, Villa A, Pascual A. Thyroid hormone negatively regulates the transcriptional activity of the beta-amyloid precursor protein gene. J Biol Chem. 1998; 273(46):30366-71.

20 Farwell AP, Dubord-Tomasetti SA. Thyroid hormone regulates the extracellular organization of laminin on astrocytes. Endocrinology. 1999;140(11):5014-21.

21 Gilbert ME, Lasley SM. Developmental thyroid hormone insufficiency and brain development: a role for brain-derived neurotrophic factor (BDNF)? Neuroscience. 2013;239: 253-70.

22 Subhadra B, Schaller K, Seeds NW. Neuroserpin up-regulation in the Alzheimer's disease brain is associated with elevated thyroid hormone receptor- $\beta 1$ and $\mathrm{HuD}$ expression. Neurochem Int. 2013;63(5):476-81.

23 Wilcoxon JS, Nadolski GJ, Samarut J, Chassande O, Redei EE. Behavioral inhibition and impaired spatial learning and memory in hypothyroid mice lacking thyroid hormone receptor alpha. Behav Brain Res. 2007;177(1):109-16.

24 Davis PJ, Goglia F, Leonard JL. Nongenomic actions of thyroid hormone. Nat Rev Endocrinol. 2016;12(2):111-21.

25 Vanderpump MPJ. Epidemiology of thyroid disorders. In: Luster M, Duntas L, Wartofsky $\mathrm{L}$, editors. The thyroid and its diseases. Springer; 2019. p. 75-85.

26 Almandoz JP, Gharib H. Hypothyroidism: etiology, diagnosis, and management. Med Clin North Am. 2012;96(2):203-21.

27 Zimmermann MB, Boelaert K. Iodine deficiency and thyroid disorders. Lancet Diabetes Endocrinol. 2015;3(4):286-95.
28 Kirsten D. The thyroid gland: physiology and pathophysiology. Neonatal Netw. 2000;19(8): 11-26.

29 Ibrahim NA, Fadeyibi IO. Ectopic thyroid: etiology, pathology and management. Hormones. 2011;10(4):261-9.

30 Khandelwal D, Tandon N. Overt and subclinical hypothyroidism: who to treat and how. Drugs. 2012;72(1):17-33.

31 Taylor PN, Albrecht D, Scholz A, GutierrezBuey G, Lazarus JH, Dayan CM, et al. Global epidemiology of hyperthyroidism and hypothyroidism. Nat Rev Endocrinol. 2018;14(5): 301.

32 Cooper DS, Biondi B. Subclinical thyroid disease. Lancet. 2012;379(9821):1142-54.

33 Graves RJ. Newly observed affection of the thyroid gland in females. London Med Surg J. 1835;7:516-7.

34 Gull WW. On cretinoid state supervening in adult life in women. Trans Clin Soc Lond. 1873;7:180-5.

35 Mathew CJ, Jose MT, Elshaikh AO, Shah L, Lee $\mathrm{R}$, Cancarevic I. Is hyperthyroidism a possible etiology of early onset dementia? Cureus. 2020;12(9)

36 Fernández-Lamo I, Montero-Pedrazuela A, Delgado-García JM, Guadaño-Ferraz A, Gruart A. Effects of thyroid hormone replacement on associative learning and hippocampal synaptic plasticity in adult hypothyroid rats. Eur J Neurosci. 2009;30(4):679-92.

37 Tan ZS, Vasan RS. Thyroid function and Alzheimer's disease. J Alzheimers Dis. 2009; 16(3):503-7.

38 Ganguli M, Burmeister LA, Seaberg EC, Belle S, DeKosky ST. Association between dementia and elevated TSH: a community-based study. Biol Psychiatry. 1996;40(8):714-25.

39 Kalmijn S, Mehta KM, Pols HA, Hofman A, Drexhage HA, Breteler MM. Subclinical hyperthyroidism and the risk of dementia. The Rotterdam study. Clin Endocrinol. 2000; 53(6):733-7.

40 Quinlan P, Horvath A, Eckerström C, Wallin A, Svensson J. Altered thyroid hormone profile in patients with Alzheimer's disease. Psychoneuroendocrinology. 2020;121:104844.

41 Samuels MH. Thyroid disease and cognition. Endocrinol Metab Clin North Am. 2014 43(2):529-43. 
42 Bunevicius R. Thyroid disorders in mental patients. Curr Opin Psychiatry. 2009;22(4): 391-5.

43 Dratman MB, Crutchfield FL, Gordon JT, Jennings AS. Iodothyronine homeostasis in rat brain during hypo- and hyperthyroidism. Am J Physiol. 1983;245(2):E185-93.

44 Loosen PT. Effects of thyroid hormones on central nervous system in aging. Psychoneuroendocrinology. 1992;17(4):355-74.

45 Cao L, Wang F, Yang Q-G, Jiang W, Wang C, Chen Y-P, et al. Reduced thyroid hormones with increased hippocampal SNAP-25 and Munc18-1 might involve cognitive impairment during aging. Behav Brain Res. 2012; 229(1):131-7.

46 Yang Y, Zhan F, Wang YC, Wang B, Shi MX, Guo C, et al. Pubertal fenvalerate exposure impairs cognitive and behavioral development partially through down-regulating hippocampal thyroid hormone receptor signaling. Toxicol Lett. 2020;332:192-201.

47 Rivas M, Naranjo JR. Thyroid hormones, learning and memory. Genes Brain Behav. 2007;6 Suppl 1:40-4.

48 De Escobar GM, Obregón MJ, Del Rey FE. Role of thyroid hormone during early brain development. Eur J Endocrinol. 2004; 151(Suppl 3):U25-37.

49 De Escobar GM, Obregón MJ, Del Rey FE. Iodine deficiency and brain development in the first half of pregnancy. Public Health Nutr. 2007;10(12A):1554-70.

50 Berbel P, Ausó E, García-Velasco JV, Molina ML, Camacho M. Role of thyroid hormones in the maturation and organisation of rat barrel cortex. Neuroscience. 2001;107(3):383-94.

51 Lavado-Autric R, Ausó E, García-Velasco JV, Arufe Mdel C, Escobar del Rey F, Berbel P, et al. Early maternal hypothyroxinemia alters histogenesis and cerebral cortex cytoarchitecture of the progeny. J Clin Invest. 2003;111(7):1073-82.

52 Ausó E, Lavado-Autric R, Cuevas E, Del Rey FE, Morreale de Escobar G, Berbel P. A moderate and transient deficiency of maternal thyroid function at the beginning of fetal neocorticogenesis alters neuronal migration. Endocrinology. 2004;145(9):4037-47.

53 Gilbert ME, Rovet J, Chen Z, Koibuchi N. Developmental thyroid hormone disruption: prevalence, environmental contaminants and neurodevelopmental consequences. Neurotoxicology. 2012;33(4):842-52.

54 Haddow JE, Palomaki GE, Allan WC, Williams JR, Knight GJ, Gagnon J, et al. Maternal thyroid deficiency during pregnancy and subsequent neuropsychological development of the child. N Engl J Med. 1999;341(8):549-55.

55 Kawahori K, Hashimoto K, Yuan X, Tsujimoto K, Hanzawa N, Hamaguchi M, et al. Mild maternal hypothyroxinemia during pregnancy induces persistent DNA hypermethylation in the hippocampal brain-derived neurotrophic factor gene in mouse offspring. Thyroid. 2018;28(3):395-406.

56 Pop VJ, Brouwers EP, Vader HL, Vulsma T, Van Baar AL, De Vijlder JJ. Maternal hypothy- roxinaemia during early pregnancy and subsequent child development: a 3-year follow-up study. Clin Endocrinol. 2003;59(3):282-8.

57 Gilbert ME. Alterations in synaptic transmission and plasticity in area CA1 of adult hippocampus following developmental hypothyroidism. Brain Res Dev Brain Res. 2004; 148(1):11-8.

58 Gilbert ME, Sui L. Dose-dependent reductions in spatial learning and synaptic function in the dentate gyrus of adult rats following developmental thyroid hormone insufficiency. Brain Res. 2006;1069(1):10-22.

59 Farahvar A, Meisami E. Novel two-dimensional morphometric maps and quantitative analysis reveal marked growth and structural recovery of the rat hippocampal regions from early hypothyroid retardation. Exp Neurol. 2007;204(2):541-55.

60 Madeira MD, Cadete-Leite A, Andrade JP, Paula-Barbosa MM. Effects of hypothyroidism upon the granular layer of the dentate gyrus in male and female adult rats: a morphometric study. J Comp Neurol. 1991;314(1):171-86.

61 Madeira MD, Sousa N, Lima-Andrade MT, Calheiros F, Cadete-Leite A, Paula-Barbosa MM. Selective vulnerability of the hippocampal pyramidal neurons to hypothyroidism in male and female rats. J Comp Neurol. 1992; 322(4):501-18.

62 Samuels MH. Psychiatric and cognitive manifestations of hypothyroidism. Curr Opin Endocrinol Diabetes Obes. 2014;21(5):377.

63 Miller KJ, Parsons TD, Whybrow PC, Van Herle K, Rasgon N, Van Herle A, et al. Verbal memory retrieval deficits associated with untreated hypothyroidism. J Neuropsychiatry Clin Neurosci. 2007;19(2):132-6.

64 Correia N, Mullally S, Cooke G, Tun TK, Phelan N, Feeney J, et al. Evidence for a specific defect in hippocampal memory in overt and subclinical hypothyroidism. J Clin Endocrinol Metab. 2009;94(10):3789-97.

65 Mulat B, Ambelu A, Yitayih S, Gela YY, Adera A, Yeshaw Y, et al. Cognitive impairment and associated factors among adult hypothyroid patients in Referral Hospitals, Amhara Region, Ethiopia: multicenter cross-sectional study. Neuropsychiatr Dis Treat. 2021;17:935.

66 Chaalal A, Poirier R, Blum D, Gillet B, Le Blanc P, Basquin M, et al. PTU-induced hypothyroidism in rats leads to several early neuropathological signs of Alzheimer's disease in the hippocampus and spatial memory impairments. Hippocampus. 2014;24(11):1381-93.

67 Breteler M, Van Duijn C, Chandra V, Fratiglioni L, Graves A, Heyman A, et al. Medical history and the risk of Alzheimer's disease: a collaborative re-analysis of case-control studies. Int J Epidemiol. 1991;20(Suppl 2):S36-42.

68 Begin M, Langlois M, Lorrain D, Cunnane S. Thyroid function and cognition during aging. Curr Gerontol Geriatr Res. 2008;2008:474868.

69 Capet C, Jego A, Denis P, Noel D, Clerc I, Cornier A, et al. Is cognitive change related to hypothyroidism reversible with replacement therapy? Rev Med Interne. 2000;21(8):672-8.
70 Alzoubi K, Aleisa A, Gerges N, Alkadhi K. Nicotine reverses adult-onset hypothyroidism-induced impairment of learning and memory: behavioral and electrophysiological studies. J Neurosci Res. 2006;84(5):944-53.

71 Beheshti F, Hosseini M, Shafei MN, Soukhtanloo M, Ghasemi S, Vafaee F, et al. The effects of Nigella sativa extract on hypothyroidismassociated learning and memory impairment during neonatal and juvenile growth in rats. Nutr Neurosci. 2017;20(1):49-59.

72 Bavarsad K, Hosseini M, Hadjzadeh MA, Sahebkar A. The effects of thyroid hormones on memory impairment and Alzheimer's disease. J Cell Physiol. 2019;234(9):14633-40.

73 Kimura N, Kumamoto T, Masuda H, Hanaoka T, Hazama Y, Okazaki T, et al. Relationship between thyroid hormone levels and regional cerebral blood flow in Alzheimer disease. Alzheimer Dis Assoc Disord. 2011; 25(2):138-43.

74 Haji M, Kimura N, Hanaoka T, Aso Y, Takemaru M, Hirano T, et al. Evaluation of regional cerebral blood flow in Alzheimer's disease patients with subclinical hypothyroidism. Dement Geriatr Cogn Disord. 2015;39(5-6):360-7.

75 Lass P, Slawek J, Derejko M, Rubello D. Neurological and psychiatric disorders in thyroid dysfunctions. The role of nuclear medicine: SPECT and PET imaging. Minerva Endocrinol. 2008;33(2):75

76 He X-S, Ma N, Pan Z-L, Wang Z-X, Li N, Zhang $\mathrm{X}-\mathrm{C}$, et al. Functional magnetic resource imaging assessment of altered brain function in hypothyroidism during working memory processing. Eur J Endocrinol. 2011; 164(6):951.

77 Cooke GE, Mullally S, Correia N, O’Mara SM, Gibney J. Hippocampal volume is decreased in adults with hypothyroidism. Thyroid. 2014;24(3):433-40.

78 Wang F, Zeng X, Zhu Y, Ning D, Liu J, Liu C, et al. Effects of thyroxine and donepezil on hippocampal acetylcholine content, acetylcholinesterase activity, synaptotagmin-1 and SNAP-25 expression in hypothyroid adult rats. Mol Med Rep. 2015;11(2):775-82.

79 Koromilas C, Liapi C, Schulpis KH, Kalafatakis $\mathrm{K}$, Zarros A, Tsakiris S. Structural and functional alterations in the hippocampus due to hypothyroidism. Metab Brain Dis. 2010;25(3):339-54.

80 Carageorgiou H, Pantos C, Zarros A, Stolakis V, Mourouzis I, Cokkinos D, et al. Changes in acetylcholinesterase, $\mathrm{Na}+, \mathrm{K}+-\mathrm{ATPase}$, and $\mathrm{Mg} 2+-$ ATPase activities in the frontal cortex and the hippocampus of hyper-and hypothyroid adult rats. Metabolism. 2007;56(8):1104-10.

81 Tousson E, Ibrahim W, Arafa N, Akela MA. Monoamine concentrations changes in the PTU-induced hypothyroid rat brain and the ameliorating role of folic acid. Hum Exp Toxicol. 2012;31(3):282-9.

82 Bauer M, Heinz A, Whybrow PC. Thyroid hormones, serotonin and mood: of synergy and significance in the adult brain. Mol Psychiatry. 2002;7(2):140-56. 
83 Buhot MC. Serotonin receptors in cognitive behaviors. Curr Opin Neurobiol. 1997;7(2): 243-54.

84 Schmitt JA, Wingen M, Ramaekers JG, Evers EA, Riedel WJ. Serotonin and human cognitive performance. Curr Pharm Des. 2006; 12(20):2473-86.

85 Bortolotto VC, Araujo SM, Pinheiro FC, Poetini MR, de Paula MT, Meichtry LB, et al. Modulation of glutamate levels and $\mathrm{Na}+, \mathrm{K}+-$ ATPase activity contributes to the chrysin memory recovery in hypothyroidism mice. Physiol Behav. 2020;222:112892.

86 Chaalal A, Poirier R, Blum D, Laroche S, Enderlin V. Thyroid hormone supplementation restores spatial memory, hippocampal markers of neuroinflammation, plasticity-related signaling molecules, and $\beta$-amyloid peptide load in hypothyroid rats. Mol Neurobiol. 2019;56(1):722-35.

87 Farwell AP, Tranter MP, Leonard JL. Thyroxine-dependent regulation of integrin-laminin interactions in astrocytes. Endocrinology. 1995 Sep;136(9):3909-15.

88 Giordano T, Pan JB, Casuto D, Watanabe S, Arneric SP. Thyroid hormone regulation of NGF, NT-3 and BDNF RNA in the adult rat brain. Brain Res Mol Brain Res. 1992;16(3-4): 239-45.

89 Lasley SM, Gilbert ME. Developmental thyroid hormone insufficiency reduces expression of brain-derived neurotrophic factor (BDNF) in adults but not in neonates. Neurotoxicol Teratol. 2011;33(4):464-72.

90 Bauer M, Silverman D, Schlagenhauf F, London E, Geist C, Van Herle K, et al. Brain glucose metabolism in hypothyroidism: a positron emission tomography study before and after thyroid hormone replacement therapy. J Clin Endocrinol Metab. 2009;94(8):2922-9.

91 Mishra J, Vishwakarma J, Malik R, Gupta K, Pandey R, Maurya SK, et al. Hypothyroidism induces interleukin-1-dependent autophagy mechanism as a key mediator of hippocampal neuronal apoptosis and cognitive decline in postnatal rats. Mol Neurobiol. 2021;58(3):1196-211.

92 Wiersinga WM. Thyroid autoimmunity. In: Szinnai G, editor. Paediatric thyroidology. Karger; 2014. Vol. 26; p. 139-57.

93 Montagna G, Imperiali M, Agazzi P, D’Aurizio F, Tozzoli R, Feldt-Rasmussen U, et al. Hashimoto's encephalopathy: a rare proteiform disorder. Autoimmun Rev. 2016;15(5):466-76.

94 Leyhe T, Müssig K. Cognitive and affective dysfunctions in autoimmune thyroiditis. Brain Behav Immun. 2014;41:261-6.

95 Djurovic M, Pereira AM, Smit JW, Vasovic O, Damjanovic S, Jemuovic Z, et al. Cognitive functioning and quality of life in patients with Hashimoto thyroiditis on long-term levothyroxine replacement. Endocrine. 2018;62(1):136-43.

96 Bladowska J, Waliszewska-Prosół M, Ejma M, Sąsiadek M. The metabolic alterations within the normal appearing brain in patients with Hashimoto's thyroiditis are correlated with hormonal changes. Metab Brain Dis. 2019; 34(1):53-60.
97 Waliszewska-Prosół M, Bladowska J, Budrewicz S, Sąsiadek M, Dziadkowiak E, Ejma M. The evaluation of Hashimoto's thyroiditis with event-related potentials and magnetic resonance spectroscopy and its relation to cognitive function. Sci Rep. 2021;11(1):1-10.

98 Waliszewska-Prosół M, Ejma M. Assessment of visual and brainstem auditory evoked potentials in patients with Hashimoto's thyroiditis. J Immunol Res. 2021;2021:3258942.

99 Roberts LM, Pattison H, Roalfe A, Franklyn J, Wilson S, Hobbs FR, et al. Is subclinical thyroid dysfunction in the elderly associated with depression or cognitive dysfunction? Ann Intern Med. 2006;145(8):573-81.

100 Wu Y, Pei Y, Wang F, Xu D, Cui W. Higher FT4 or TSH below the normal range are associated with increased risk of dementia: a meta-analysis of 11 studies. Sci Rep. 2016 6(1):31975-8.

101 Folkestad L, Brandt F, Lillevang-Johansen M, Brix TH, Hegedüs L. Graves' disease and toxic nodular goiter, aggravated by duration of hyperthyroidism, are associated with $\mathrm{Al}$ zheimer's and vascular dementia: a registrybased long-term follow-up of two large cohorts. Thyroid. 2020;30(5):672-80.

102 Papaleontiou M. Higher risks of dementia in untreated and undertreated individuals with hyperthyroidism. Clin Thyroidol. 2020; 32(4):170-3.

103 Reddy V, Taha W, Kundumadam S, Khan M. Atrial fibrillation and hyperthyroidism: a literature review. Indian Heart J. 2017;69(4): $545-50$.

104 Tang X, Song Z-H, Wang D, Yang J, Cardoso MA, Zhou J-B, et al. Spectrum of thyroid dysfunction and dementia: a dose-response metaanalysis of 344,248 individuals from cohort studies. Endocr Connect. 2021;10(4):410-21.

105 Elberling TV, Danielsen ER, Rasmussen AK, Feldt-Rasmussen U, Waldemar G, Thomsen C. Reduced myo-inositol and total choline measured with cerebral MRS in acute thyrotoxic Graves' disease. Neurology. 2003;60(1):142-5.

106 Danielsen ER, Elberling T, Rasmussen AK, Dock J, Hørding M, Perrild H, et al. Reduced parietooccipital white matter glutamine measured by proton magnetic resonance spectroscopy in treated Graves' disease patients. J Clin Endocrinol Metab. 2008;93(8):3192-8.

107 Schreckenberger M, Egle U, Drecker S, Buchholz H, Weber M, Bartenstein P, et al. Positron emission tomography reveals correlations between brain metabolism and mood changes in hyperthyroidism. J Clin Endocrinol Metab. 2006;91(12):4786-91.

108 Zhu D-F, Wang Z-X, Zhang D-R, Pan Z-L, $\mathrm{He} \mathrm{S}, \mathrm{Hu} \mathrm{X}-\mathrm{P}$, et al. fMRI revealed neural substrate for reversible working memory dysfunction in subclinical hypothyroidism. Brain. 2006;129(11):2923-30.

109 de Jong FJ, Masaki K, Chen H, Remaley AT, Breteler MM, Petrovitch $\mathrm{H}$, et al. Thyroid function, the risk of dementia and neuropathologic changes: the Honolulu-Asia aging study. Neurobiol Aging. 2009;30(4):600-6.
110 Gan EH, Pearce SH. The thyroid in mind cognitive function and low thyrotropin in older people. J Clin Endocrinol Metab. 2012; 97(10):3438-49.

111 Fu AL, Zhou CY, Chen X. Thyroid hormone prevents cognitive deficit in a mouse model of Alzheimer's disease. Neuropharmacology. 2010;58(4-5):722-9.

112 Bianchi G, Solaroli E, Zaccheroni V, Grossi G, Bargossi AM, Melchionda N, et al. Oxidative stress and anti-oxidant metabolites in patients with hyperthyroidism: effect of treatement. Horm Metab Res. 1999;31(11):620-4.

113 Villanueva I, Alva-Sánchez C, Pacheco-Rosado $\mathrm{J}$. The role of thyroid hormones as inductors of oxidative stress and neurodegeneration. Oxid Med Cell Longev. 2013;2013:218145.

114 Li L-X, Yang T, Guo L, Wang Y-D, Tang $\mathrm{C}-\mathrm{H}, \mathrm{Li} \mathrm{Q}$, et al. Serum tau levels are increased in patients with hyperthyroidism. Neurosci Lett. 2020;729:135003.

115 Döbert N, Hamscho N, Menzel C, Peters J, Frölich L, Tsolakis A, et al. Subclinical hyperthyroidism in dementia and correlation of the metabolic index in FDG-PET. Acta Med Austriaca. 2003;30(5):130.

116 Fukui T, Hasegawa Y, Takenaka H. Hyperthyroid dementia: clinicoradiological findings and response to treatment. J Neurol Sci. 2001;184(1):81-8.

117 Rieben C, Segna D, da Costa BR, Collet T-H, Chaker L, Aubert CE, et al. Subclinical thyroid dysfunction and the risk of cognitive decline: a meta-analysis of prospective cohort studies. J Clin Endocrinol Metab. 2016;101(12):4945-54.

118 Aubert CE, Bauer DC, da Costa BR, Feller M, Rieben C, Simonsick EM, et al. The association between subclinical thyroid dysfunction and dementia: the Health, Aging and Body Composition (Health ABC) Study. Clin Endocrinol. 2017;87(5):617-26.

119 de Jong FJ, den Heijer T, Visser TJ, de Rijke YB, Drexhage HA, Hofman A, et al. Thyroid hormones, dementia, and atrophy of the medial temporal lobe. J Clin Endocrinol Metab. 2006;91(7):2569-73.

120 Yeap BB, Alfonso H, Chubb SP, Puri G, Hankey GJ, Flicker L, et al. Higher free thyroxine levels predict increased incidence of dementia in older men: the Health in Men Study. J Clin Endocrinol Metab. 2012;97(12):E2230-7.

121 George KM, Lutsey PL, Selvin E, Palta P, Windham BG, Folsom AR. Association between thyroid dysfunction and incident dementia in the atherosclerosis risk in communities neurocognitive study. J Endocrinol Metab. 2019;9(4):82.

122 Formiga F, Ferrer A, Padros G, Contra A, Corbella X, Pujol R. Thyroid status and functional and cognitive status at baseline and survival after 3 years of follow-up: the OCTABAIX study. Eur J Endocrinol. 2014;170(1):69-75.

123 Ceresini G, Lauretani F, Maggio M, Ceda GP, Morganti S, Usberti E, et al. Thyroid function abnormalities and cognitive impairment in elderly people: results of the Invecchiare in Chianti study. J Am Geriatr Soc. 2009;57(1):89-93 